Review

\title{
Acoustic Vibration Approach for Detecting Faults in Hydroelectric Units: A Review
}

\author{
Fang Dao, Yun Zeng *, Yidong Zou, Xiang Li and Jing Qian
}

check for updates

Citation: Dao, F.; Zeng, Y.; Zou, Y.; Li, X.; Qian, J. Acoustic Vibration Approach for Detecting Faults in Hydroelectric Units: A Review. Energies 2021, 14, 7840. https:// doi.org/10.3390/en14237840

Academic Editors: Matteo Postacchini and Wencheng Guo

Received: 26 October 2021

Accepted: 19 November 2021

Published: 23 November 2021

Publisher's Note: MDPI stays neutral with regard to jurisdictional claims in published maps and institutional affiliations.

Copyright: (c) 2021 by the authors. Licensee MDPI, Basel, Switzerland. This article is an open access article distributed under the terms and conditions of the Creative Commons Attribution (CC BY) license (https:// creativecommons.org/licenses/by/ $4.0 /)$.
Faculty of Metallurgy and Energy Engineering, Kunming University of Science and Technology, Kunming 650031, China; daofang@stu.kust.edu.cn (F.D.); 20192202117@stu.kust.edu.cn (Y.Z.); lixiang2@stu.kust.edu.cn (X.L.); qj0117@kust.edu.cn (J.Q.)

* Correspondence: zengyun001@kust.edu.cn

\begin{abstract}
The health of the hydroelectric generator determines the safe, stable, and reliable operation of the hydropower station. In order to keep the hydroelectric generator in a better state of health and avoid accidents, it is crucial to detect its faults. In recent years, fault detection methods based on sound and vibration signals have gradually become research hotspots due to their high sensitivity, achievable continuous dynamic monitoring, and easy adaptation to complex environments. Therefore, this paper is a supplement to the existing state monitoring and fault diagnosis system of the hydroelectric generator; it divides the hydroelectric generator into two significant parts: hydrogenerator and hydro-turbine, and summarizes the research and application of fault detect technology based on sound signal vibration in hydroelectric generator and introduces some new technology developments in recent years, and puts forward the existing problems in the current research and future development directions, and it is expected to provides some reference for the research on fault diagnosis of the hydroelectric generator.
\end{abstract}

Keywords: hydroelectric generator; acoustic vibration signal; fault detection; crack; de-noising

\section{Introduction}

With the increase in global energy demand and climate change, renewable energy plays an increasingly important role [1]. It can be seen that hydropower is still the primary source of renewable energy soon [2,3]. As of the end of 2019, there were approximately $1.3 \times 10^{9} \mathrm{~kW}$ of total installed hydropower capacity and $4.3 \times 10^{15} \mathrm{kWh}$ of annual power generation worldwide. In 2035, the global annual power generation is expected to reach $6.1 \times 10^{15} \mathrm{kWh}$, and the installed hydropower capacity is $1.75 \times 10^{9} \mathrm{~kW}$ [4]. It can be seen that hydropower is still the primary source of renewable energy soon and has ample space for development [5]. As the core equipment for water resource utilization, the hydroelectric generator's reliable and safe operation is the foundation, and failures will cause serious consequences or even catastrophic accidents [6]. Therefore, the hydroelectric generator's maintenance and fault detection are critical, which also made the research on the faults of rotating machinery such as the hydroelectric generator started in the 1960s [7].

Due to the development of big data technology, signal processing technology, and other technologies, the fault detection of the hydroelectric generator has gradually entered the era of automation and intelligence [8,9].

The fault detection methods of the hydroelectric generator can be divided into three categories [10], as shown in Table 1. (1) Model-based fault detection method. As early as 1976, Willsky put forward the concept of model-based fault detection. In recent years, the model-based fault detection method has been extended to structural damage detection, shaft crack detection, induction motor, aerospace, and other fields [11]. In the fault detection of the hydroelectric generator, this method mainly optimizes the parameters of the original monitoring data and establishes a new model. The model has good accuracy and predictability, but it relies on expert experience and is only suitable for analyzing 
specific hydropower stations, limiting its application to a certain extent [12]. (2) Process analysis method based on working conditions. This method mainly studies and analyzes the vibration characteristics of the hydroelectric generator from the steady-state level of a single working condition. However, the hydroelectric power generation system contains a variety of transient processes. The fault detection method of a single working condition process is challenging to extend to the entire hydroelectric generator. In other working conditions, its applicability is poor [13,14]. (3) Intelligent detection method based on signal feature extraction. Compared with the fault detection methods described in (1) and (2) above, it is suitable for fault detection under various working conditions and complex structures of the hydroelectric generator; it can solve those complex problems that cannot be established analytical models or rely on expert knowledge. It has many advantages in fault detection applications, such as high accuracy, strong robustness, and strong generalization ability [15]. The most widely used intelligent detection methods include extreme learning machines [16], artificial neural networks [17,18], expert systems [19], and support vector machines [20]. A fault detection method based on statistical process control (SPC) has been proposed in recent years. It compares and analyzes statistical reference data with real-time statistical data to determine whether there is a fault or abnormality [21]. When extracting fault features, Kernel Independent Component Analysis (KICA) can estimate the number of fault signals of the single-channel vibration signal to extract more evident fault characteristics [22]. The current fault detection methods for the hydroelectric generator are mostly displacement, acceleration from the data type. There are few studies on fault detection based on sound and vibration signals.

Table 1. Faults detection methods of the hydroelectric generator.

\section{Faults Detection Methods of} the Hydroelectric Generator

Model-based fault detection method

Process analysis method based on working condition

Intelligent detection method based on signal feature extraction
Advantages

Good accuracy and predictability

Obtain reliable signal resources

Good data processing ability, suitable for different working conditions
Disadvantages

Strong dependence and small

application range

Applicability is poor

This method is mainly in the research and has few practical applications

Fault detection based on sound signal vibration is mainly used for pipelines and mechanical parts. Detecting pipeline leakage through acoustic vibration can quickly and accurately detect the location of pipeline leakage and provide early warning of pipeline leakage [23]. Reference [24] proposed a calculation model for predicting gearbox noise from steady-state dynamic response to acoustic vibration calculation in response to the noise problem generated during gearbox operation. This model can play a role in the design phase of the car, that is, reduce the noise of its reducer and transmission. In addition, the detection method based on acoustic vibration is also applied to fruit detection. By studying the vibration characteristics of the fruit, this method can predict the quality of the fruit and reduce the damage of the fruit during transportation [25]. The use of sound signals to detect faults or defects has the following advantages [26]: (1) high sensitivity to defect recognition, (2) continuous dynamic monitoring, and (3) high adaptability to complex environments.

This paper divides the hydroelectric generator into two parts: hydro-generator and hydro-turbine. Then, it summarizes the fault detection technology based on sound signal vibration for each part and introduces some new developments in recent years. This paper serves as a valuable supplement to the existing hydropower generator condition monitoring and fault diagnosis system, hoping to provide a specific reference value for related research on the hydropower generator's efficient and reliable operation. 


\section{Acoustic Vibration Detection of the Hydro-Turbine Faults}

The hydro-turbine is essential equipment for hydropower stations to convert water energy into mechanical energy. The types of hydro-turbine include (1) Francis turbines, (2) Tubular turbines, (3) Impulse turbines, and (4) Diagonal flow turbines. At present, the related research on the use of the sound signal to identify and diagnose hydro-turbine faults is mainly concentrated on the turbine runner blades [27-29], and most of them are research and exploration in the experimental environment.

\subsection{Cavitation Erosion Phenomenon of Turbine Runner}

Cavitation is one of the leading causes of damage to the runner of hydro-turbine [30]. Although the cavitation produced by the turbine in the working process is not destructive, the vibration, noise, and cavitation can damage the turbine. It can directly damage the structure of the turbine, increase maintenance costs, and reduce the machine's service life [31]. Therefore, the identification and diagnosis of cavitation are of great significance.

Reference [32] proposed a method for detecting and diagnosing cavitation phenomenon based on ultrasonic vibration, which measured the cavitation phenomenon of Kaplan turbine under a series of working conditions. Vibration and ultrasonic sensors are used, respectively, installed on the lower guide gear and the guide tube access door of the top cover according to the $+X$ and $-Y$ directions. The structure of the monitoring system is shown in Figure 1. The normalized power spectral density method (PSD) is used to process the spectrogram; when the frequency range is $20 \mathrm{~Hz}$ to $20 \mathrm{kHz}$, the strength of the cavitation signal is expressed by the vibration frequency; when the frequency range is $20 \mathrm{kHz}$ to $250 \mathrm{kHz}$, the strength of the cavitation signal is expressed by the ultrasonic frequency. The noise generated during the turbine's operation is mostly much lower than the frequency generated by the cavitation signal, which is negligible. Although cavitation signal strength can be used to detect the cavitation phenomenon of hydraulic turbines, under some complex working conditions, low-frequency noise will affect the collected ultrasonic signals, making the detection results inaccurate.

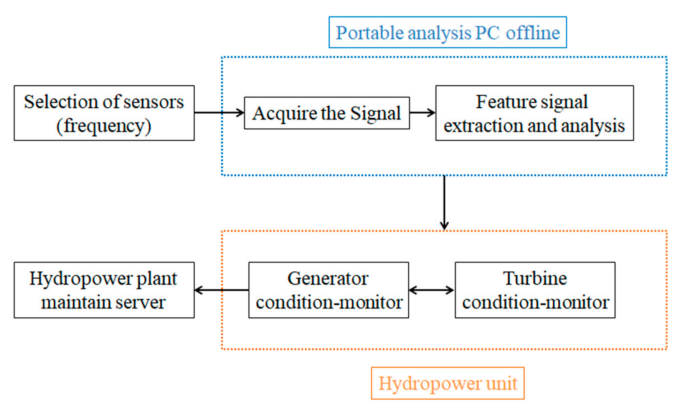

Figure 1. Structure of cavitation erosion monitoring system based on ultrasonic vibration.

Faria et al. [33] introduced a method for identifying minor cavitation defects in the hydro-turbine based on sound signal monitoring. In this method, they designed two sets of controlled experiments: For turbines with no apparent defects in the runner blades and the hydro-turbine with minor defects, the defect is that a spherical cavity with a diameter of $8 \mathrm{~mm}$ is located on the suction side of the runner blades; The sensor installed on the draft tube of the hydro-turbine with a frequency range of $20 \mathrm{kHz}$ to $1 \mathrm{MHz}$ is adopted. They are compared by measuring the sound and vibration signals of the two sets of hydro-turbines at three driving frequencies of $40 \mathrm{~Hz}, 50 \mathrm{~Hz}$, and $60 \mathrm{~Hz}$, and the RMS comparison curve is drawn. From the results, it can be seen that the two curves do not overlap. Although there are complex flow characteristics and bubble collapse frequency patterns around the turbine runner blades, the sound signal changes caused by tiny defects in the runner blades can also cause significant changes. This point can be used to monitor and early warning of cavitation erosion of hydro-turbines in the early stages of formation. However, this test is only for acoustic vibration monitoring of tiny cavitation phenomena on the runner blades, 
which is poor versatility. To study cavitation erosion in other parts and need to collect the corresponding location data.

Given some of the problems in the above experiments, references [34,35] have carried out related research. Reference [34] studied and analyzed the influence of the installation position of the acoustic sensor on the detection of cavitation erosion of the hydraulic turbine and used three acoustic sensors for signal collection. Two acoustic sensors have a frequency range of $100 \mathrm{kHz}$ to $1 \mathrm{MHz}$, and the other has a frequency range of $100 \mathrm{kHz}$ to $900 \mathrm{kHz}$. All three acoustic sensors are equipped with a $100 \mathrm{kHz}$ high-pass filter. The upper cover of the volute and the upper cover of the guide vane are, respectively, in the frequency range of $100 \mathrm{kHz}$ to $1 \mathrm{MHz}$ acoustic sensor, and on the surface of the discharge ring is an acoustic sensor with a frequency range of $100 \mathrm{kHz}$ to $900 \mathrm{kHz}$. The working condition of the turbine is increased from the partial load condition to the maximum discharge condition. The sampling frequency of the three acoustic sensors is 4 MSs, and the duration of one measurement is $0.92 \mathrm{~s}$. Calculate the root mean square value (RMS) of the measured data. It can be seen from the results that as the flow rate increases, the RMS value of the acoustic sensors located on the volute and the guide vane cover shows a similar trend and changes significantly when the set threshold is exceeded; the RMS value of the acoustic sensor installed on the surface of the discharge ring does not change much before and after the threshold. Therefore, in the hydroelectric generator, the most suitable location for monitoring cavitation is the hydro-turbine.

Reference [35] improved and optimized the detection method of hydro-turbine cavitation through experiments. First, simplify the structure of the turbine and build a test bench. The test bench is shown in Figure 2. It consists of a generator, a conveyor belt, a driveshaft, a rotating disk, and a water tank. The rotating disk is enclosed in a tank filled with water, and the acoustic sensor and accelerometer are installed at the positions shown in the figure. The motor drives the conveyor belt, and the power is transmitted to the driveshaft to drive the rotation of the disk to simulate the rotation of the runner; the piezoelectric sheet is used to form an excitation signal to simulate the cavitation phenomenon of the hydro-turbine. The experiment selects static and rotating in the air, static and rotating in the water; these four rotating disks under different working conditions are subjected to different excitation modes. There are three excitation modes: (1) Fundamental frequency excitation mode $\left(f_{1}=1 \mathrm{kHz}-2 \mathrm{kHz}, f_{2}=10 \mathrm{kHz}-11 \mathrm{kHz}, f_{3}=20 \mathrm{kHz}-21 \mathrm{kHz}\right)$; (2) Fundamental frequency + low frequency $f_{4}(22.1 \mathrm{~Hz})$ excitation mode; (3) Fundamental frequency + low frequency $f_{4}+$ vortex frequency $f_{5}(1.4 \mathrm{~Hz})$ excitation mode, as shown in Table 2. The collected signal can be obtained by consistency, frequency response function, and Hilbert transform analysis. The sensor with the best acoustic signal is located on the driveshaft. For sensors installed at fixed locations, such as near a sink, sound conduction in water is better than conduction in air, which also means that the sound vibration of the disk is mainly transmitted through water. After analysis and sorting, it can be seen that selecting the rotation axis as the placement position of the acoustic sensor to detect the cavitation phenomenon will have a better effect.

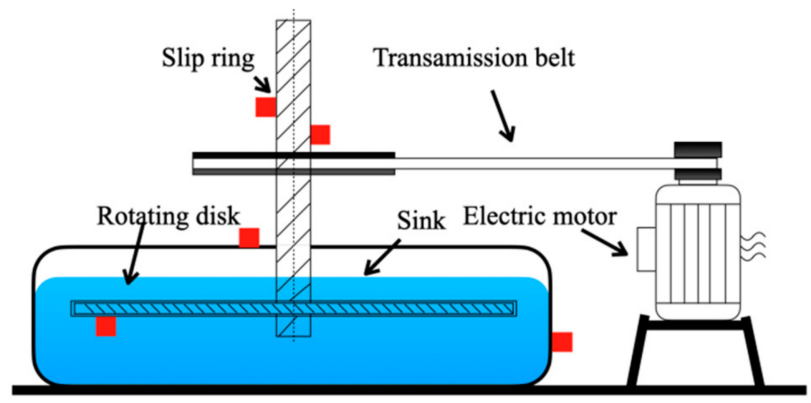

Figure 2. Schematic of hydro-turbine model test stand. 
Table 2. Cavitation simulation test of hydro-turbine.

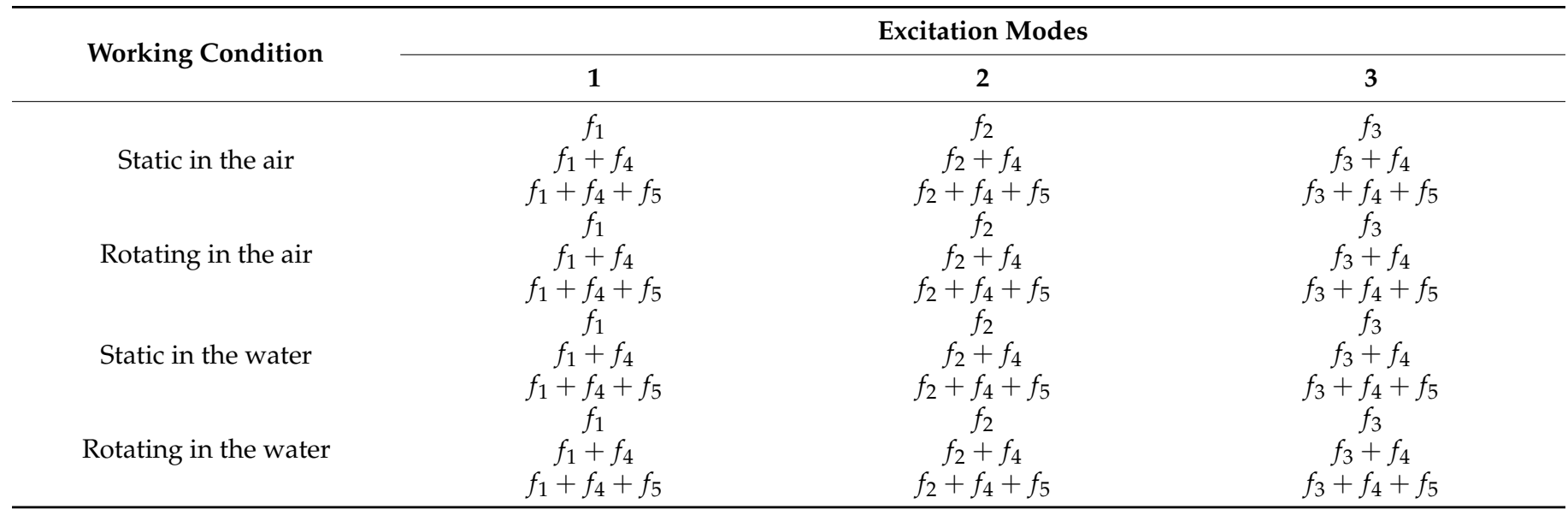

\subsection{Cracks in the Blades of Turbine Runner}

The cracks in the turbine runner blades have always been an essential factor affecting hydropower stations' stable and safe operation. Dynamic stress caused by resonance is often one of the leading causes of cracks in turbine runner blades [36]. Repairing cracks can reduce damage to a certain extent, but frequent shutdown and welding will reduce the ultimate strength of the runner and cause economic losses. Therefore, online monitoring and early warning of runner blade cracks are vital [37]. Monitoring and early warning of cracks in runner blades based on sound signals can adapt to the turbine's complex environment and have high detection sensitivity.

The sound signal is affected by factors such as the transmission distance and the complexity of the hydro-turbine structure during the transmission process, and attenuation will occur, leading to a certain degree of distortion. Therefore, to study the cracks of the runner blades, it is necessary to study the attenuation characteristics of the acoustic signal on the runner blades. Reference [38] used simulating the lead core crack to study the runner blade's attenuation performance. Lead core breaking points are arranged from top to bottom in the four blades of the runner, and sensors are installed on the top plane of each blade to collect the energy and amplitude emitted by each point when it breaks, and use the relative attenuation rate to describe the attenuation of the sound signal characteristic. The experimental data and the processed results are available. As the distance increases, the attenuation rate increases, indicating that the distance of sound propagation has a more significant impact on the amplitude and energy; in the interface attenuation test, the interface attenuation rate of the two sensors is different, one being smaller, indicating that the primary influence of the interface on the attenuation comes from the size.

The above data are to analyze the sound attenuation as a whole. Detailed analysis of the information requires many data, so it is necessary to find a method that can effectively deal with the crack sound signal. Reference [39] verifies the feasibility of wavelet packet technology to analyze the attenuation characteristics of the acoustic signal of the turbine runner crack and performs the $i$-layer wavelet decomposition on the collected acoustic signal:

$$
\left\{\begin{array}{c}
P^{(0,0)}(t)=S(t) \\
P^{(i+1,2 j+1)}=\sum_{k} H(k-2 t) P^{(i . j)}(t) \\
P^{(i+1,2 j)}=\sum_{k} G(k-2 t) P^{(i . j)}(t)
\end{array}\right.
$$

In the above, $i=0,1,2, \ldots, j=0,1, \ldots, 2^{i}-1, t=1,2, \ldots, 2^{I-i}, I=\log _{2} N ; N$ is the number of $t ; G$ and $H$ are wavelet decomposition filters; $P^{(i, j)}$ represents the $j$-th wavelet packet coefficient of the $i$-th layer. 
Normalize the signal energy in each frequency band of each layer:

$$
\begin{gathered}
C_{i j}=E_{i j} / E_{i} \\
E_{i}=\left(\sum_{j=0}^{2^{i}-1}\left|E_{i j}\right|^{2}\right)^{\frac{1}{2}}
\end{gathered}
$$

In the above, $E_{i j}$ represents the energy corresponding to each frequency band signal in the $i$-th layer, $E_{i}$ Calculate according to Equation (3).

The reference value is taken as the point closest to the sensor, and the relative attenuation rate of energy after normalization is calculated:

$$
A_{P m}^{i j}=20 \log \left(B^{i j}(P m) / B^{i j}(P 1)\right)
$$

In the above, $B(P m)$ is the energy of the signal; $P m$ represents the lead breaking point; $m=1,2 \ldots, 5$.

The data after wavelet packet analysis and the original data can be fitted and compared to have their attenuation characteristic curves the same, which shows that the sound signal processed by the wavelet packet technology can accurately reflect the attenuation characteristics of the original signal.

Determining the location of cracks is one of the primary purposes of monitoring the blades of turbine runners using acoustic vibration signals. Due to the complexity of the internal structure of the turbine and the diversity of background noise, the sound signal sampled by the sensor is very complicated, and the signal needs to be processed. Generally speaking, the localization of the crack source is divided into three parts: signal acquisition, feature extraction, and location. First, the acoustic signal sensor collects 13 parameters, including energy, signal strength, amplitude, and ring count. The kernel independent component analysis (KICA) method is used to extract feature parameters [40]. The basic principle of KICA is to use the method of non-linear function $\Phi$ mapping. It turns the sample point $x_{i}$ of the input space into the sample point $\Phi\left(x_{i}\right)$ of the feature space and performs linear independent component analysis on the data. This method can reduce the dimensionality of the data, improve the positioning accuracy, and reduce the transmission pressure. References $[40,41]$ used two methods to locate the crack source: wavelet neural network and support vector machine. The principle of a wavelet neural network is to minimize the error function, and the SCG algorithm adaptively adjusts the waveform, scale, and network weight of the wavelet base. The wavelet network model can be expressed as:

$$
\begin{gathered}
y_{i}^{P}=f\left(\sum_{j=1}^{N} w_{i j} \Psi_{a, b}\left(F / a_{j}\right)\right) \\
F=\sum_{k=1}^{M} w_{j k} x_{k}^{P}-b_{j}
\end{gathered}
$$

In the above, $M$ is the number of input layer units; $N$ is the number of hidden layer units; $L$ is the number of output layer units, $k=1,2 \ldots, M, i=1,2 \ldots, L, j=1,2 \ldots, N$; $a_{j}$ is the scale factor; $b_{j}$ is the displacement factor; $w_{i j}$ is the weight of the unit connecting the output layer and the hidden layer.

The basic principle of the support vector machine is to map the data in the sample space to a higher-dimensional linear feature space through a specific non-linear function $\varphi(x)$. The optimal classification hyperplane is constructed in the feature space, the distance between the hyper-plane and the sample sets of different classes is the largest, and the discriminant function of the classifier is used to achieve correct classification. The classification hyper-plane can be expressed as:

$$
w \varphi(x)+b=0
$$


In the above, $x$ is the input vector; $w$ is the weight vector; $b$ is the bias coefficient.

After the test, the mean square error calculation of the collected positioning data can be obtained. The mean square error of the positioning method using support vector machine is 0.1623 , which is less than the mean square error using wavelet neural network is 0.58. The support vector machine does not need information, such as the exact position of the sensor or the time of occurrence of the crack to overcome the influence of the complex internal structure. However, the above methods are all based on sample data for analysis and calculation and have not been applied to actual crack tests. References [42,43] identify and monitor actual runner blade cracks using acoustic vibration signals. Reference [42] obtained the relationship between the crack growth rate and the count rate of the acoustic sensor after theoretical derivation:

$$
\frac{d H}{d n}=\frac{B}{C^{p / m}}\left(\frac{d a}{d n}\right)^{p / m}=B^{\prime}\left(\frac{d a}{d n}\right)^{p^{\prime}}
$$

In the above, $H$ is the ringing count; $n$ is the number of fatigue; $B$ is the thickness of the blade; $a$ is the crack length; $C, m$, and $p$ are specific material constants; $\frac{d H}{d n}$ and $\frac{d a}{d n}$ are linear in logarithmic coordinates.

The count rate detected by the sensor is linearly related to the curve of the crack growth rate. The fitting correlation coefficient between them is more than $90 \%$, consistent with the theoretical conclusion. By detecting the change rate of the sound signal, the crack growth rate can be calculated and used to evaluate the blade's safety. Reference [43] conducted a monitoring test of acoustic vibration signals on blade cracks, proposed and verified the relationship between the energy change rate of the acoustic signal and the crack growth rate, and established a correlation model on this basis:

$$
\ln \frac{d a}{d N}=0.175 \ln \frac{d E}{d N}-7.234
$$

In the above, $E$ is the cumulative energy of the sound vibration signal; $a$ is the crack length; $N$ is the number of loading cycles.

The model predicts the crack length at a particular stage, consistent with the actual crack length.

\section{Acoustic Vibration Detection of the Hydro-Generator Faults}

The hydro-generator is a device that converts the mechanical energy generated by the rotation of the hydro-turbine into electrical energy. Its structure and performance play a vital role in the stable and efficient operation of the entire power station [44,45]. In the operating conditions of the generator set, due to the air movement, the imbalance of the stator and rotor, the friction and collision of mechanical parts, and the electromagnetic effect, the generator set produces shock and vibration, thereby causing the noise. The noise of hydro-generator is generally divided into mechanical, air, and electromagnetic noise [46-48]. At present, the research on sound and vibration signals of hydro-generator is mainly to collect and identify abnormal sounds and filter processing of background noise.

The vibration signal of the hydro-generator fluctuates wildly, which is a non-stationary signal. The steady or low-frequency signal is proper, and the high-frequency signal is noise. The fault analysis of the hydro-generator needs to extract the fault characteristics from the vibration signal and the vibration collected by the sensor. Most of the signals are mixed with complex background noise, so filtering the background noise is helpful to analyze and diagnose faults [49].

In the hydro-generator, winding insulation is the most critical component, but the insulation components will degenerate with the passage of working time. In severe cases, partial discharge will occur, which will cause the generator to fail and cause substantial economic losses [50]. Therefore, it is necessary to detect and evaluate the insulation state of the winding, and the partial discharge signal analysis is an effective method for evaluation and diagnosis [51]. However, in measuring the partial discharge signal of the generator, 
it will be affected by noise and interference, which will cause severe errors in the measured dataset. Effective de-noising methods play a vital role in identifying and detecting partial discharge signals; the de-noising methods can be divided into hardware-based de-noising and software-based de-noising [52], as shown in Table 3.

Table 3. Conclusion of de-noising method of partial discharge signal.

\begin{tabular}{|c|c|c|c|}
\hline Methods of De-Noising & Reference(s) & Principle & Features \\
\hline \multirow{3}{*}{ Hardware-based } & {$[53,54]$} & Gating approach & $\begin{array}{l}\text { Simple operation, strong practicability, } \\
\text { but easy to lose the real signal }\end{array}$ \\
\hline & {$[55]$} & Balanced circuit & $\begin{array}{l}\text { Mature technology, high recognition rate, } \\
\text { but unable to eliminate the interference } \\
\text { generated by the generator itself }\end{array}$ \\
\hline & {$[56]$} & $\begin{array}{l}\text { Multiple sensors noise rejection on } \\
\text { pulse-by-pulse basis }\end{array}$ & $\begin{array}{l}\text { Unable to distinguish partial discharge } \\
\text { noise of winding parts }\end{array}$ \\
\hline \multirow{6}{*}{ Software-based } & [57] & Time-domain method & $\begin{array}{l}\text { The calculation is simple, but the } \\
\text { accuracy of the de-noising result is low }\end{array}$ \\
\hline & [58] & Moving averaging technique & $\begin{array}{l}\text { Reduce the relative level of noise, but it } \\
\text { will produce signal distortion }\end{array}$ \\
\hline & [59] & $\begin{array}{l}\text { Waveform analysis in combination with } \\
\text { pattern recognition }\end{array}$ & Disturbances can be separated from PD \\
\hline & {$[60]$} & Fast Fourier transform & $\begin{array}{l}\text { It can accurately extract signal features } \\
\text { with high accuracy, but when its } \\
\text { spectrum overlaps with the PD signal's } \\
\text { spectrum, noise or interference cannot } \\
\text { be suppressed. }\end{array}$ \\
\hline & [61-63] & Wavelet transform & $\begin{array}{l}\text { Reduce distortion and good de-noising } \\
\text { effect, but the threshold selection is } \\
\text { complicated and depends on } \\
\text { professional knowledge }\end{array}$ \\
\hline & [64] & Wavelet Shrinkage Scheme & $\begin{array}{l}\text { De-noising effect is better than wavelet } \\
\text { transform, but this method takes longer }\end{array}$ \\
\hline
\end{tabular}

In 2009, Y.W. Youn et al. proposed a comprehensive noise suppression method for the noise in partial discharge signals that cannot eliminate traditional noise suppression methods [65]. It consists of two noise suppression methods: the adjacent phase induction noise suppressing technique and the adaptive noise suppression technique, which executes the two noise suppression methods sequentially on the collected signal data. The adaptive noise suppression technique is divided into three steps. The first is to use fuzzy logic to classify noise in stages and remove pattern noise samples with similar phases. This process is very effective in suppressing general noise and equal amplitude noise. Secondly, it removes the low-count pulse, it denoises the fastest, but it is invalid for periodic noise; finally, the grouping characteristics of partial discharges are used for de-noising. This method can remove periodic noise. The adjacent phase induction noise suppressing technique can remove most of the noise, but the accuracy is high, the calculation process is cumbersome, and the stability is poor.

Reference [62] uses wavelet threshold shrinkage technology to identify and filter the noise generated in the partial discharge signal of the generator set and uses the principle that the background noise has a smaller wavelet coefficient in the wavelet domain than the partial discharge signal so that the processed local discharge signal is kept above the noise threshold to the maximum in the wavelet domain. Among them, signal processing includes determining the number of wavelet decomposition layers and filters. The purpose of determining the number of wavelet decomposition levels is to select the most appropriate decomposition level in the wavelet domain to represent a specific signal accurately. The number of decomposition levels has a significant impact on the de-noising results. Too few decomposition levels make the de-noising effect very poor. If there are too 
many decomposition layers, the de-noising effect is not necessarily better, and unnecessary processing is added [66].

The selection method of the filter adopts wavelet selection based on stationary wavelet transform-based wavelet selection (SWTBWS). This method is the same as the wavelet selection method based on correlation. It selects the stationary wavelet transform (SWT) in impulse interference, calculates the filter that produces the most significant absolute value, and improves two aspects at the same time: First, the fast wavelet transform calculates the discrete inner product of each layer, rather than the correlation between the signal and the filter; second, the iterated wavelet function does not have to match the equivalent filter bank exactly. Through this de-noising method, the broadband noise in the partial discharge of the hydro-generator is significantly reduced, the processing time and calculation steps are shortened, and the recognition sensitivity and efficiency are improved.

In addition to the use of wavelet analysis to process the partial discharge signal of the generator set, the artificial neural network can also be used to identify the partial discharge signal to filter out the useless background noise [67]. The identification process is shown in Figure 3, and the dataset is noise filtered. Furthermore, extract its features and then use these features as the input vector of the neural network. However, for some intense noise and crosstalk signal interference, the recognition rate of this method is low, and the de-noising effect is not apparent.

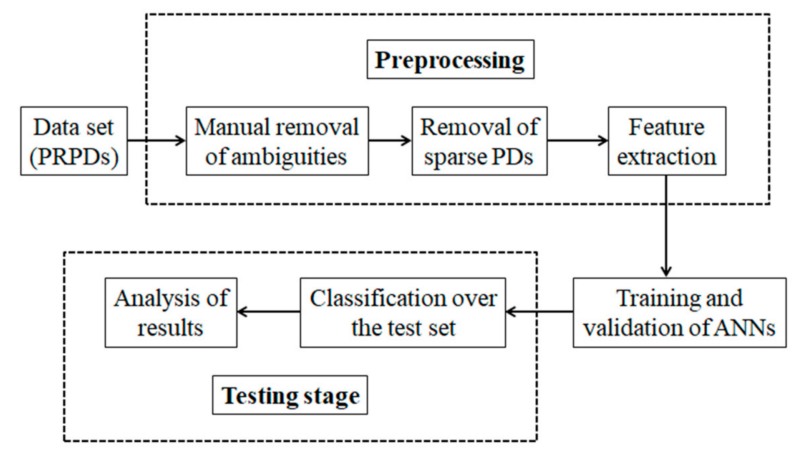

Figure 3. Flowchart of partial discharge signal recognition by artificial neural network.

Given the above problems, Reference [68] improved the recognition method and proposed a phase-resolved partial discharge (PRPD) image de-noising method. The process is shown in Figure 4.

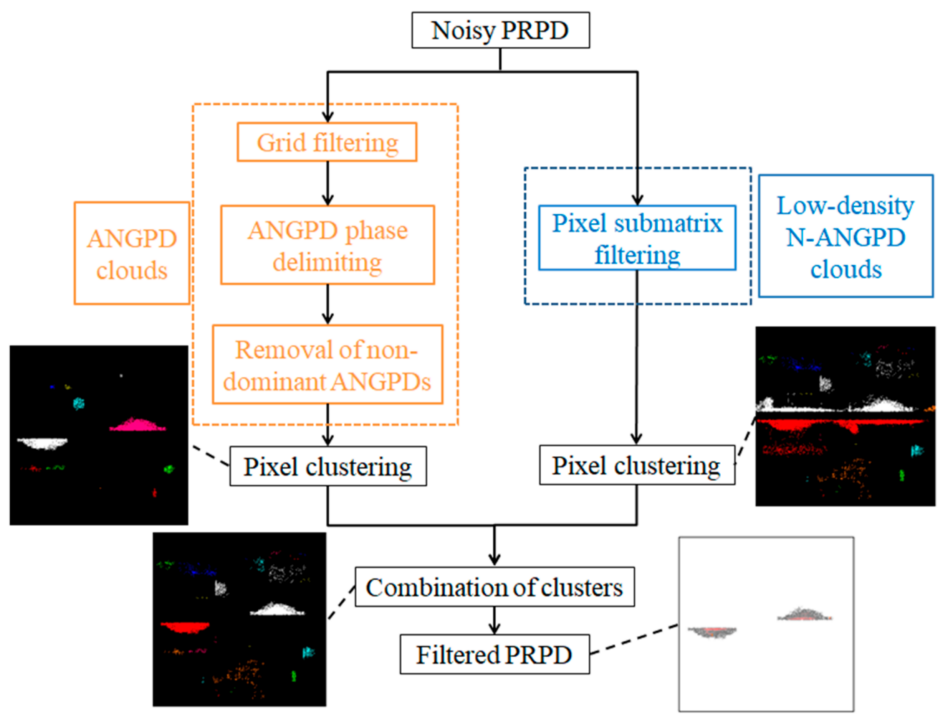

Figure 4. Flowchart of PRPD. 
When a PRPD dataset is input, two grid filtering and pixel residual filtering paths are adopted to filter the waveform. The purpose of grid filtering is to extract a pair of dominant adjacent to noise gap partial discharges (ANGPD) clouds and remove false discharge signals around the ANGPD cloud without distorting the results. This filtering will also remove effective low-density non-adjacent to noise gap partial discharges (n-ANGPD) cloud. These effective $n-A N G P D$ clouds can be restored by adopting the pixel residual filter path, composed of the pixel residual matrix technology, a low-strength filtering method that can remove the sparse noise between different n-ANGPD clouds. After obtaining the output of the two filtering paths, merge the different cloud clusters into temporary samples. Analyzing the ANGPD clustering in the temporary sample can determine whether the primary partial discharge data set in the input sample is adjacent or non-adjacent noise gap partial discharge. Finally, the filtered phase decomposition partial discharge source is obtained.

As a non-linear filtering technique, morphological filtering can extract the noise in the partial discharge signal, according to Equation (10) [69]. Equation (10) is generally used to extract or remove peak noise such as burrs, as shown in Figure 5.

$$
(f \circ g)(n)=[(f \Theta g) \oplus \mathrm{g}](n)
$$

In the above, $f \circ g$ is the open operation of function $f$ with respect to $g$, and function $g$ is a structural element; $f \Theta g$ is the expansion expression of function $f ; f \oplus g$ is the corrosion expression of function $f$.

After the original spectrum is subtracted by morphological filtering, the noise spectrum dominated by white noise is obtained. At this time, the classical threshold is introduced into the spectrum [70], and the frequency of the maximum value more significant than the threshold is identified as the discrete spectrum interference frequency value. The interference suppression method using morphological filtering can effectively remove white noise interference and reduce the algorithm's time complexity, but there is a problem that structural elements are challenging to determine in practical applications.

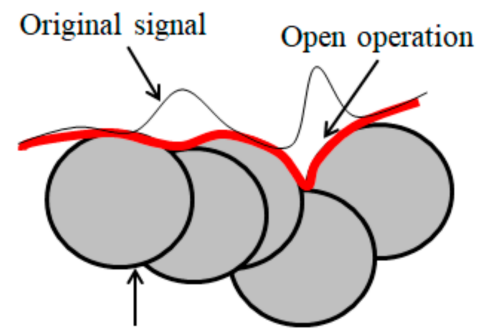

Structural element

Figure 5. Opening a signal by a circular structuring element.

Research based on sound and vibration signals can remove background noise and process and analyze the vibration of the generator set. In collecting the vibration signal of the generator set, the vibration signal collected by the sensor will be accompanied by solid background noise. Whether it is a fault diagnosis of a hydraulic turbine or a generator set, signal processing is required to extract the fault characteristics, so signal processing is highly critical; it determines the success of the diagnosis [71]. Reference [72] proposed a new wavelet transform to denoise the collected vibration signals. Its basic principle is to use unbiased likelihood estimation to process the vibration signals collected by the sensor and determine a threshold. The principle of determination is the vibration signal. The variance with the de-noising signal is the smallest, and then the part that exceeds the threshold is removed. Using this method in the de-noising process and comparing it with the traditional wavelet transform, it can be found that the new method has a faster calculation speed and can obtain a more satisfactory de-noising result. Due to the complexity of the generator set structure and the diversity of operating conditions, its self-vibration often 
manifests itself as substantial uncertainty and harmonic superposition. Micro-vibration affects the vibration control performance of the hydroelectric generator shaft system and affects the non-linear dynamic characteristics of the shaft system [73]. Reference [46] uses a combination of bounded acoustic vibration signals and harmonic excitation to establish the unit's performance. The external random excitation model, in which the harmonic excitation model is based on the following Equation:

$$
f(t)=\sum_{i=1}^{n} p_{i} \sin \left(\Omega_{i} t+\alpha_{i}\right)+f \xi(t)
$$

In the above, $i$ is the external excitation amplitude of the harmonic; $\Omega_{i}$ is the external excitation frequency of the harmonic; $\alpha_{i}$ is a random stage, $f$ is a constant.

The bounded acoustic vibration model is expressed as $\xi(t)$, which is calculated as follows:

$$
\xi(t)=A \sin \left[\omega_{0} t+\sigma B(t)+\gamma\right]
$$

In the above, $A$ is the amplitude; $\omega_{0}$ is the center frequency; $\sigma$ is the spectral width coefficient; $B(t)$ is the linear process function of the unit; $\gamma$ is a uniformly distributed random variable in $[0,2 \pi)$.

This model is mainly used to study the influence of external random excitation and related parameters (damping, mass, and stiffness) on the non-linear dynamic characteristics of the coupled system. It also provides further ideas for the dynamic theory of hydrogenerator shafting.

Reference [74] used a method of combining exponential function and Huber estimation to solve the noise problem in the measurement test of the generator set, constructing the robust objective function, and realizing the robust identification of the result. The specific expression is as follows:

$$
\min J(\alpha)=1-\frac{1}{T} \int_{0}^{T} e^{-\left[v^{2}|| v_{i}\left|\leq k+\left(2 k|v|-k^{2}\right)\right||v|>k\right]} d t
$$

In the above, $N$ is the number of samples; $I$ is the sampling frequency; $v_{i}$ is the ratio of the guide vane opening in the experiment to the guide vane opening calculated by the identification model; $s$ is the standard deviation.

Compared with the conventional objective function, the vital objective function automatically removes insufficient data, which reduces the data processing steps before identification.

Some scholars have recently proposed the hydro-generator fault diagnosis method that combines stray magnetic flux and acoustics [75]. The test uses a fault simulator to compare the stray flux and acoustically recorded spectra of healthy machines and machines that intentionally introduce defects; to search for the characteristics of the most common mechanical and electrical defects. The results show that this method can identify most faults, but it has not been applied to the sizeable hydroelectric generator.

\section{Discussion about Research Directions and Prospects}

As the single unit capacity of the hydroelectric generator continues to grow, the requirements for the safety and reliability of various components are also increasing [76]. The fault diagnosis technology of the hydroelectric generator based on sound signal vibration can provide more unit status for the current diagnosis and detection system and improve the hydroelectric generator's fault diagnosis and early warning capability. However, to realize the large-scale application of this technology and breakthroughs, some other work needs to be carried out. The challenges and development directions faced by the current research results include the following points:

1. The fault characteristics of the components of the hydroelectric generator or under special working conditions. The current fault diagnosis technology based on sound vibration mainly focuses on detecting turbine runner blade cracks and turbine cavitation status from the reference review. However, there is no effective acoustic vibration 
detection method for particular operating conditions, such as generator stator and rotor distortion, mutation statuses, such as runner blade mud by sand wear, and water bucket shedding. Therefore, the study of sound vibration to solve the problem of faults in other components or working conditions of the hydro-generator unit can be a valuable supplement to the existing unit condition monitoring and fault diagnosis system and further improve the safety of the hydroelectric generator operation.

2. Selection of the location of sound and vibration signal collection. The on-site signal data collection is a crucial link in the fault detection of acoustic and vibration signals. The fault can be detected and located only by collecting the required raw signal data for analysis and research. The collection of signals requires a sound collection system. At present, the related technology of the sound collection system is very mature, and it has the advantages of low cost and high recognition rate [77]. However, the internal structure of the hydroelectric generator is very complicated, and a variety of sound signals will be generated during operation. Therefore, selecting the most suitable location for monitoring and collecting sound signals in the hydroelectric generator is necessary. In the current research, the measurement position of the sound signal (the installation position of the sound sensor) has not been carefully studied and summarized. This problem needs to be further solved in the follow-up research.

3. Consider the problem of insufficient noise removal during signal acquisition. In the actual sound signal collection process, due to the complexity of the structure and operation of the hydroelectric generator, the collected signal will be mixed with a large amount of high-frequency noise, which will interfere with the measurement result necessary to denoise the signal. Among them, the principle of de-noising includes two points: smoothness and similarity; that is, the de-noised sound signal and the original signal should have the same smoothness, and the variance estimation should be a minor variance in the worst case. Scholars have carried out much work on this problem, mainly including the following methods: threshold method, empirical mode decomposition, wavelet de-noising, adaptive filtering, morphological filtering, Fourier transform, and so on. These methods have a specific suppression effect on noise, but they cannot completely filter out the noise in the signal. For example, wavelet de-noising has a good suppression effect on white noise, but the number of decomposition layers and mother wavelet need to be considered in the analysis process. The problem is adaptive filtering can automatically adjust the filtering parameters but requires exceptionally high stability; the threshold law requires a lot of complex calculations to determine the threshold. Therefore, further research and discussion require further research and discussion on which method should be selected to process the collected sound and vibration signals without distortion and with high accuracy.

4. Research based on the "mutation" perspective of acoustic vibration signals. Related engineering problems show that detection methods based on sound and vibration signals effectively solve some specific hydroelectric generator equipment failures, but there is a need for further breakthroughs in the theory of refined detection of local details. Use the "mutation" signal generated by sound vibration in emergencies (blade breakage, bucket falling off, and shaft friction.) to detect the operating status of the entire unit, which is actually to avoid the theoretical bottleneck of fine sound vibration detection to research from the perspective of "signal mutation." There is no related literature report on this technical method.

5. Studies have shown that the unit will show the failure of the hydroelectric generator in the form of vibration. Therefore, it is an excellent technical path to study how to carry out fault prediction and online diagnosis of units through sound and vibration signal detection. 


\title{
5. Conclusions
}

The health of the hydroelectric generator is an essential key factor for the safe, stable, and reliable operation of hydropower stations. The fault diagnosis technology of the hydroelectric generator based on sound signal vibration can be researched from two aspects: hydro-turbine and hydro-generator. (1) For hydro-turbine, sound vibration signals are mainly used for monitoring and early warning of two aspects of runner blade cracks and cavitation; (2) For hydro-generator, the primary research is on signal de-noising.

In general, using sound and vibration signals described in this article to detect and identify the faults of the hydroelectric generator has advantages that other fault detection methods do not have and has great potential for development:

1. Fault location and dynamic monitoring;

2. Identify weak signs of early failure and warning;

3. According to the working condition parameters of each acoustic vibration variable, a fault trend prediction model is established to evaluate and manage the health status of the unit;

4. The method of acoustic vibration fault detection applies to the complex internal structure of hydropower unit, which can refine the acoustic vibration characteristics of crucial components and detect and analyze them;

5. Use the "mutation" perspective of acoustic vibration signals to carry out research. This method avoids the theoretical and engineering technical bottlenecks of fine acoustic vibration detection and uses the sudden change detection of acoustic vibration signals to evaluate the sudden changes of the hydropower unit (blade breakage, bucket falling off).

At the same time, since the current development is in its infancy, there are still some problems to be solved.

Author Contributions: Conceptualization, F.D. and Y.Z. (Yun Zeng); methodology, Y.Z. (Yun Zeng); validation, F.D., Y.Z. (Yun Zeng) and Y.Z. (Yidong Zou); formal analysis, F.D., Y.Z. (Yun Zeng), Y.Z. (Yidong Zou), X.L., J.Q.; writing—original draft preparation, F.D. and Y.Z. (Yidong Zou); writing-review and editing, Y.Z. (Yun Zeng). All authors have read and agreed to the published version of the manuscript.

Funding: This research is supported by the National Natural Foundation of China under the research grants of 52079059 and 51869007.

Institutional Review Board Statement: Not applicable.

Informed Consent Statement: Not applicable.

Data Availability Statement: All data used to support the findings of this study are included within the article.

Conflicts of Interest: The authors declare no conflict of interest.

\author{
Abbreviations \\ SPC Statistical process control \\ PSD Power spectral density \\ RMS Root mean square \\ KICA Kernel independent component analysis \\ SCG Scaled conjugate gradient \\ SWTBWS Stationary wavelet transform based wavelet selection \\ SWT Stationary wavelet transform \\ PRPD Phase-resolved partial discharge \\ ANGPD Adjacent to noise gap partial discharges \\ n-ANGPD Non-adjacent to noise gap partial discharges
}




\section{References}

1. Li, X.-Z.; Chen, Z.-J.; Fan, X.-C.; Cheng, Z.-J. Hydropower development situation and prospects in China. Renew. Sustain. Energy Rev. 2018, 82, 232-239. [CrossRef]

2. Morane, F.; Lopezm, C.; Moore, N.; Müller, N.; Hyndman, D.W. Sustainable hydropower in the 21st century. Proc. Natl. Acad. Sci. USA 2018, 115, 11891-11898. [CrossRef]

3. Jadoont, R.; Alim, K.; Hussain, S.; Wasim, A.; Jahanzaib, M. Sustaining power production in hydropower stations of developing countries. Sustain. Energy Technol. Assess. 2020, 37, 100637.

4. Zhou, J.; Du, X.; Zhou, X. Current Status and Future Trends of Global Hydropower Development. China Electr. Power 2020, 26-29.

5. Huntj, D.; Byers, E.; Wada, Y.; Parkinson, S.; Gernaat, D.E.H.J.; Langan, S.; van Vuuren, D.P.; Riahi, K. Global resource potential of seasonal pumped hydropower storage for energy and water storage. Nat. Commun. 2020, 11, 947.

6. Kuznetsov, N.V.; Yuldashev, M.V.; Yuldashev, R.V. Analytical-numerical analysis of closed-form dynamic model of SayanoShushenskaya hydropower plant: Stability, oscillations, and accident. Commun. Nonlinear Sci. Numer. Simul. 2021, $93,105530$. [CrossRef]

7. Siola, R.; Michaels, J.; Stranovsky, G.; Zelingher, S.; Walter, T.; Tecza, J.; Hutchison, J. Initial use of an on-line expert system for condition assessment of pumped storage hydromachines. In Proceedings of the Waterpower'97, Atlanta, GA, USA, 5-8 August 1997; ASCE: Reston, VA, USA, 1997.

8. Liao, G.-P.; Gao, W.; Yang, G.-J.; Guo, M.F. Hydroelectric Generating Unit Fault Diagnosis Using 1-D Convolutional Neural Network and Gated Recurrent Unit in Small Hydro. IEEE Sens. J. 2019, 19, 9352-9363. [CrossRef]

9. Pan, L.; An, X.; Zhou, Y. Multi-dimension health assessment and diagnosis of hydropower unit based on big data. J. Hydraul. Engineeing 2018, 49, 1178-1186.

10. Zhu, W.; Zhou, J.; Li, C.; Xue, X. Residual diagnosis model based on wavelet neutral network and its application to hydroelectric generator unit. In Proceedings of the IEEE 12th International Conference on Networking, Sensing and Control, Taipei, Taiwan, 9-11 April 2015.

11. Gao, Z.; Cecati, C.; Ding, S.X. A survey of fault diagnosis and fault-tolerant techniques-Part I: Fault diagnosis with model-based and signal-based approaches. IEEE Trans. Ind. Electron. 2015, 62, 3757-3767. [CrossRef]

12. Zhouk, B.; Zhangj, Y.; Shan, Y.; Ge, M.F.; Ge, Z.Y.; Cao, G.N. A Hybrid Multi-Objective Optimization Model for Vibration Tendency Prediction of Hydropower Generators. Sensors 2019, 19, 2055.

13. Zhang, L.; Wu, Q.; Ma, Z.; Wang, X. Transient vibration analysis of unit-plant structure for hydropower station in sudden load increasing process. Mech. Syst. Signal. Process. 2019, 120, 486-504. [CrossRef]

14. Wu, Q.; Zhang, L.; Ma, Z.; Wang, X. Vibration characteristics of the unit-plant structure of a hydropower station under transient load-up process. J. Vib. Shock. 2019, 38, 53-61.

15. Gao, Z.; Cecati, C.; Ding, S.X. A survey of fault diagnosis and fault-tolerant techniques—Part II: Fault diagnosis with knowledgebased and hybrid/active approaches. IEEE Trans. Ind. Electron. 2015, 62, 3768-3774. [CrossRef]

16. Fu, W.; Wang, K.; Tan, J.; Shao, K. Vibration Tendency Prediction Approach for Hydropower Generator Fused with Multiscale Dominant Ingredient Chaotic Analysis, Adaptive Mutation Grey Wolf Optimizer, and KELM. Complexity 2020, $2020,4516132$. [CrossRef]

17. Fu, C.; Ye, L.; Liu, Y.; Yu, R.; Iung, B.; Cheng, Y.; Zeng, Y. Predictive Maintenance in Intelligent-Control-Maintenance-Management System for Hydroelectric Generating Unit. IEEE Trans. Energy Convers. 2004, 19, 179-186. [CrossRef]

18. Khelil, Y.; Graton, G.; Djeziri, M.; Outbib, R. Fault detection and isolation in marine diesel engines: A generic methodology. IFAC Proc. Vol. 2012, 45, 964-969. [CrossRef]

19. Xu, X.; Yan, X.; Sheng, C.; Yuan, C.; Xu, D.; Yang, J.-B. A Belief Rule-Based Expert System for Fault Diagnosis of Marine Diesel Engines. IEEE Trans. Syst. Man Cybern. Syst. 2017, 50, 656-672. [CrossRef]

20. Wang, Z.; Yao, L.; Cai, Y. Rolling bearing fault diagnosis using generalized refined composite multiscale sample entropy and optimized support vector machine. Measurement 2020, 156, 107574. [CrossRef]

21. Yan, Y.; Cai, J.; Li, T.; Zhang, W.; Sun, L. Fault prognosis of HVAC air handling unit and its components using hidden-semi Markov model and statistical process control. Energy Build. 2021, 240, 110875. [CrossRef]

22. Fang, L.; Sun, H. Study on EEMD-Based KICA and Its Application in Fault-Feature Extraction of Rotating Machinery. Appl. Sci. 2018, 8, 1441. [CrossRef]

23. Liang, W.; Zhang, L.; Xu, Q.; Yan, C. Gas pipeline leakage detection based on acoustic technology. Eng. Fail. Anal. 2013, 31, 1-7. [CrossRef]

24. Han, J.; Liu, Y.; Yu, S.; Zhao, S.; Ma, H. Acoustic-vibration analysis of the gear-bearing-housing coupled system. Appl. Acoust. 2021, 178, 108024. [CrossRef]

25. Ding, C.; Feng, Z.; Wang, D.; Cui, D.; Li, W. Acoustic vibration technology: Toward a promising fruit quality detection method. Compr. Rev. Food Sci. Food Saf. 2021, 20, 1655-1680. [CrossRef]

26. Carrasco, Á.; Méndez, F.; Leaman, F.; Vicuña, C.M. Short Review of the Use of Acoustic Emissions for Detection and Monitoring of Cracks. Acoust. Aust. 2021, 49, 273-280. [CrossRef]

27. Drtina, P.; Sallaberger, M. Hydraulic turbines-basic principles and state-of-the-art computational fluid dynamics applications. Proc. Inst. Mech. Eng. Part. C J. Mech. Eng. Sci. 1999, 213, 85-102. [CrossRef] 
28. Iliev, I.; Trivedi, C.; Dahlhaug, O.G. Variable-speed operation of Francis turbines: A review of the perspectives and challenges. Renew. Sustain. Energy Rev. 2019, 103, 109-121. [CrossRef]

29. Tiwari, G.; Kumar, J.; Prasad, V.; Patel, V.K. Utility of CFD in the design and performance analysis of hydraulic turbines-A review. Energy Rep. 2020, 6, 2410-2429. [CrossRef]

30. Khare, R.; Prasad, V. Prediction of cavitation and its mitigation techniques in hydraulic turbines-A review. Ocean. Eng. 2021, 221, 108512.

31. Singh, R.; Tiwari, S.K.; Mishra, S.K. Cavitation Erosion in Hydraulic Turbine Components and Mitigation by Coatings: Current Status and Future Needs. J. Mater. Eng. Perform. 2011, 21, 1539-1551. [CrossRef]

32. Liu, S.-Y.; Wang, S.-Q. Cavitations monitoring and diagnosis of hydropower turbine on line based on vibration and ultrasound acoustic. In Proceedings of the 2007 International Conference on Machine Learning and Cybernetics, Hong Kong, China, 19-22 August 2007.

33. Faria, M.T.C.; Queiroz, F.R.; Medeiros, E.B.; Martinez, C.B. Acoustic Emission Tests in the Monitoring of Cavitation Erosion in Hydraulic Turbines. In Proceedings of the ASME 2013 International Mechanical Engineering Congress and Exposition, San Diego, CA, USA, 15-21 November 2013.

34. Schmidt, H.; Kirschner, O.; Riedelbauch, S.; Necker, J.; Kopf, E.; Rieg, M.; Arantes, G.; Wessiak, M.; Mayrhuber, J. Influence of the vibro-acoustic sensor position on cavitation detection in a Kaplan turbine. IOP Conf. Ser. Earth Environ. Sci. 2014, 22, 052006. [CrossRef]

35. Valentín, D.; Presas, A.; Egusquiza, M.; Valero, C.; Egusquiza, E. Transmission of High Frequency Vibrations in Rotating Systems. Application to Cavitation Detection in Hydraulic Turbines. Appl. Sci. 2018, 8, 451. [CrossRef]

36. Li, Z.; Wang, Y.; Li, T.; Liu, F.; Ji, J. The dynamic characteristics of the ultimate strength of a turbine runner blade under hydraulic excitation. Energy Sources Part A Recovery Util. Environ. Eff. 2019, 41, 3127-3137. [CrossRef]

37. Zhu, D.; Tao, R.; Xiao, R.; Pan, L. Solving the runner blade crack problem for a Francis hydro-turbine operating under conditioncomplexity. Renew. Energy 2020, 149, 298-320. [CrossRef]

38. Wang, X.H.; Hu, H.W.; Shao, Y.M.; Fu, J.Q. The Distance Attenuation of Acoustic Emission Signals in Turbine Runners. Appl. Mech. Mater. 2011, 103, 262-267. [CrossRef]

39. Wang, X.H.; Zhu, C.M.; Mao, H.L.; Huang, Z.F. Wavelet packet analysis for the propagation of acoustic emission signals across turbine runners. NDT E Int. 2009, 42, 42-46. [CrossRef]

40. Wang, X.H.; Mao, H.L.; Hu, H.W.; Zhang, Z. Crack localization in hydraulic turbine blades based on kernel independent component analysis and wavelet neural network. Int. J. Comput. Intell. Syst. 2013, 6, 1116-1124. [CrossRef]

41. Wang, X.H.; Mao, H.L.; Zhuc, M.; Huang, Z.F. Damage localization in hydraulic turbine blades using kernel-independent component analysis and support vector machines. Proc. Inst. Mech. Eng. Part C J. Mech. Eng. Sci. 2008, 223, 525-529. [CrossRef]

42. Wang, X.-H.; Zhu, C.-M.; Mao, H.-L.; Huang, Z.-F. Feasibility analysis for monitoring fatigue crack in hydraulic turbine blades using acoustic emission technique. J. Cent. South Univ. Technol. 2009, 16, 444-450. [CrossRef]

43. Zhang, Z.; Yang, G.; Hu, K. Prediction of Fatigue Crack Growth in Gas Turbine Engine Blades Using Acoustic Emission. Sensors 2018, 18, 1321. [CrossRef] [PubMed]

44. Xu, B.; Chen, D.; Li, H.; Zhuang, K.; Hu, X.; Li, J.; Skjelbred, H.I.; Kong, J.; Patelli, E. Priority analysis for risk factors of equipment in a hydraulic turbine generator unit. J. Loss Prev. Process. Ind. 2019, 58, 1-7. [CrossRef]

45. Gozdowiak, A. Faulty Synchronization of Salient Pole Synchronous Hydro Generator. Energies 2020, 13, 5491. [CrossRef]

46. Sun, W.; Guo, Z. Mathematical modeling and nonlinear vibration analysis of a coupled hydro-generator shaft-foundation system. Commun. Nonlinear Sci. Numer. Simul. 2021, 98, 105776. [CrossRef]

47. Dirani, H.C.; Merkhouf, A.; Giroux, A.-M.; Kedjar, B.; Al-Haddad, K. Impact of real air-gap nonuniformity on the electromagnetic forces of a large hydro-generator. IEEE Trans. Ind. Electron. 2018, 65, 8464-8475. [CrossRef]

48. Li, R.; Li, C.; Peng, X.; Wei, W. Electromagnetic Vibration Simulation of a 250-MW Large Hydropower Generator with Rotor Eccentricity and Rotor Deformation. Energies 2017, 10, 2155. [CrossRef]

49. Liu, Y.; Wang, F.; Liu, L. Detection of Weak Impulse Signal under Strong Noise Background. J. Vib. Meas. Diagn. 2019, 39, 168-175, 228-289.

50. Soltani, R.; Gaillardet, Z.P.; Chichkin, I.; Ledger, B. Investigation of Partial Discharge Activity and Insulation Life of a Large Hydro Generator. In Proceedings of the 2019 IEEE Electrical Insulation Conference (EIC), Calgary, Canada, 16-19 June 2019.

51. Herath, T.; Kumara, S.; Bandara, K.; Wijayakulasooriya, J.; Fernando, M.; Jayanatha, G.A. Field verification of a novel and simple partial discharge detection method for generator applications. IET Sci. Meas. Technol. 2020, 14, 835-843. [CrossRef]

52. Luo, Y.; Li, Z.; Wang, H. A review of online partial discharge measurement of large generators. Energies 2017, 10, 1694. [CrossRef]

53. $\mathrm{Su}, \mathrm{Q}$. Partial discharge measurements on generators using a noise gating system. In Proceedings of the AUPEC/EECON'99, Darwin, Australia, 1 January 1999.

54. Stone, G.C. Partial discharge diagnostics and electrical equipment insulation condition assessment. IEEE Trans. Dielectr. Electr. Insul. 2005, 12, 891-904. [CrossRef]

55. Kurtz, M.; Lyles, J.; Stone, G. Application of partial discharge testing to hydro generator maintenance. IEEE Trans. Power Appar. Syst. 1984, 8, 2148-2157. [CrossRef] 
56. Itoh, K.; Kaneda, Y.; Kitamura, S.; Kimura, K.; Nishimura, A.; Tanaka, T.; Tokura, H.; Okada, I. New noise rejection techniques on pulse-by-pulse basis for on-line partial discharge measurement of turbine generators. IEEE Trans. Energy Convers. 1996, 11, 585-594. [CrossRef]

57. Gulski, E.; Kreuger, F. Computer-aided recognition of discharge sources. IEEE Trans. Electr. Insul. 1992, 27, 82-92. [CrossRef]

58. Van Brunt, R.J.; Cernyar, E.; von Glahn, P. Importance of unraveling memory propagation effects in interpreting data on partial discharge statistics. IEEE Trans. Electr. Insul. 1993, 28, 905-916. [CrossRef]

59. Mor, A.R.; Heredia, L.C.; Muñoz, F. New clustering techniques based on current peak value, charge and energy calculations for separation of partial discharge sources. IEEE Trans. Dielectr. Electr. Insul. 2017, 24, 340-348. [CrossRef]

60. Luo, X.; Niu, H.; Wu, J. A modified method of suppressing narrow-band interference using FFT power spectrum. In Proceedings of the 2013 IEEE International Conference on Solid Dielectrics (ICSD), Bologna, Italy, 30 June-4 July 2013.

61. Chan, J.C.; Ma, H.; Saha, T.K.; Ekanayake, C. A novel level-based automatic wavelet selection scheme for partial discharge measurement. In Proceedings of the 2012 22nd Australasian Universities Power Engineering Conference (AUPEC), Bali, Indonesia, 26-29 September 2012.

62. Carvalho, A.T.; Lima, A.C.; Cunha, C.F.F.C.; Petraglia, M. Identification of partial discharges immersed in noise in large hydro-generators based on improved wavelet selection methods. Measurement 2015, 75, 122-133. [CrossRef]

63. Altay, Ö.; Kalenderli, Ö. Wavelet base selection for de-noising and extraction of partial discharge pulses in noisy environment. IET Sci. Meas. Technol. 2015, 9, 276-284. [CrossRef]

64. LI, Y.; LI, Z. Application of a Novel Wavelet Shrinkage Scheme to Partial Discharge Signal De-noising of Large Generators. Appl. Sci. 2020, 10, 2162. [CrossRef]

65. Youn, Y.; Kang, D.; Yi, S.; Shin, B.C. A synthetic noise suppressing algorithm for partial discharge signals of generators. In Proceedings of the 2009 Transmission \& Distribution Conference \& Exposition: Asia and Pacific, Seoul, Korea, 26-30 October 2009.

66. Xiaorong, W.; Zongjun, G.; Yong, S.; Zhang, Y. Extraction of partial discharge pulse via wavelet shrinkage. In Proceedings of the Proceedings of the 6th International Conference on Properties and Applications of Dielectric Materials (Cat No 00CH36347), Xi'an, China, 21-26 June 2000.

67. Oliveira, R.M.S.D.; Araújo, R.C.F.; Barros, F.J.B.; Segundo, A.P.; Zampolo, R.F.; Fonseca, W.; Dmitriev, V.; Brasil, F.S. A System Based on Artificial Neural Networks for Automatic Classification of Hydro-generator Stator Windings Partial Discharges. J. Microw. Optoelectron. Electromagn. Appl. 2017, 16, 628-645. [CrossRef]

68. Araújo, R.C.F.; DE Oliveira, R.M.S.; Brasil, F.S.; Barros, F.J.B. Novel Features and PRPD Image De-noising Method for Improved; Single-Source Partial Discharges Classification in On-Line Hydro-Generators. Energies 2021, 14, 3267. [CrossRef]

69. Luo, Y.; Li, Z.; Cheng, S.; Wang, H. A Method for Suppression Discrete Spectrum Interference in Partial Discharge of Generators Combining Mathematical Morphology Filter and Spectrum Correction. Proc. CSEE 2019, 39, 6403-6412.

70. Donoho, D.L. De-noising by soft-thresholding. IEEE Trans. Inf. Theory 1995, 41, 613-627. [CrossRef]

71. Ehya, H.; Nysveen, A.; Groth, I.; Mork, B.A. Detailed Magnetic Field Monitoring of Short Circuit Defects of Excitation Winding in Hydro-generator. In Proceedings of the 2020 International Conference on Electrical Machines (ICEM), online, 23-26 August 2020.

72. Peng, W.J.; Luo, X.Q.; Guo, P.C. Vibration Signal Preprocessing of Hydraulic Generator Set Based on the Second Generation Wavelet. Proc. CSEE 2007, 27, 103-107.

73. Huang, Z.; Zhou, J.; Yang, M.; Zhang, Y. Vibration characteristics of a hydraulic generator unit rotor system with parallel misalignment and rub-impact. Arch. Appl. Mech. 2011, 81, 829-838. [CrossRef]

74. Yue, L.; Xue, A.; Xu, F.; Bi, T.; Yang, Q.; Yan, J.; Li, B. A Two-step Robust Parameter Identification Method for Dynamic Parameters of Hydro Generator Governor Based on Field Test Data. Proc. CSEE 2018, 38, 3163-3171.

75. Kedjar, B.; Merkhouf, A.; Al-Haddad, K. Large synchronous machines diagnosis based on air-gap and stray fluxes-An overview. In Proceedings of the 2020 International Conference on Electrical Machines (ICEM), online, 23-26 August 2020.

76. Sun, L.; Guo, P.; Yan, J. Transient analysis of load rejection for a high-head Francis turbine based on structured overset mesh. Renew. Energy 2021, 171, 658-671. [CrossRef]

77. Moreno-Ramírez, C.; Iniesta, C.; González, A.; Olazagoitia, J.L. Development and Characterization of a Low-Cost Sensors System for an Acoustic Test Bench. Sensors 2020, 20, 6663. [CrossRef] 